(Argonne National Laboratory) was programme chairman, and Dr. R. H. Busey (Oak Ridge National Laboratory) was local arrangements chairman.

The Hugh M. Huffman Memorial Lecture, astablished in memory of the founder of the Calorimetry Conference, was given by Prof. J. W. Stout (University of Chicago) on the subject "Magnetic Entropy in Ionic Crystals". Prof. Stout gave a stimulating lecture on the magnetic contribution to the entropy of ionic salts of the transition metals, discussing the theoretical considerations and the results obtained from low-temperature heat-capacity measurements and from experiments on magnetic susceptibility, paramagnetic resonance, and optical absorption.

Several papers were devoted to a perennial concern of the Conference : the improvement of temperaturemeasuring devices. Further tests of the germanium resistance thermometers developed at the Bell Telephone Laboratories were described, with $\mathrm{H}$. Plump reporting on "Low Temperature Thermometry at the National Bureau of Standards" in the range $2-20^{\circ} \mathrm{K}$., and C. van Rijn, H. van Dijk and M. Durieux (Kamerlingh Onnes Laboratorium, Leyden) reporting on "Calibration of a Germanium Resistance Thermometer at Liquid Helium and Liquid Hydrogen Temperatures". These devices show such encouraging promise for precision temperature measurements from $1^{\circ}$ to $20^{\circ} \mathrm{K}$. that a committee has been seeking a manufacturer of additional germanium thermometers for further testing. $P$. Lindenfeld (Rutgers University), chairman of the committee, reported that the Minneapolis-Honeywell Regulator Co. has become interested, and G. Halverson of that Company showed several pilot models.

Results in a quite different temperature region were presented by J. P. Evans (National Bureau of Standards), who described the development of platinum resistance thermometers for the Intermational Temperature Scale from $630 \cdot 5^{\circ}$ to $1,063^{\circ} \mathrm{C}$. It is expected that the use of such thermometers will simplify and smooth the scale, as well as provide greater precision and reproducibility than is possible with present thermometric instruments. Also, the use of thermistors for measuring small changes of temperature in solution calorimetry was described in several papers. A notable example was the paper by G. R. Argue, E. E. Mercer, and J. W. Cobble (Purdue University) on "An Ultrasensitive Thermistor Microcalorimeter" for the determination of the heats of solution of the heavy elements with quantities as small as 5 or $10 \mu \mathrm{gm}$.

Several authors reported on applications of calorimetric techniques to solid-state physics. J. E.
Kunzler (Bell Telephone Laboratories), for example, discussed methods for the observation of very small amounts of energy-between $10^{-2}$ and $10^{2}$ ergsand the application of these techniques to investigations of magneto-thermal oscillations of single crystals of bismuth and the adiabatic demagnetization and heat capacity of ferrimagnets.

A subject of great interest to calorimetrists measuring or analysing heat capacities was presented by B. N. Brockhouse (Atomic Energy of Canada, Ltd.) in an invited paper on "Dispersion Curves and Frequency Distributions of Lattice Vibrations from Neutron Scattering". A novel cryostat for lowtemperature calorimetry from $4^{\circ}$ to $80^{\circ} \mathrm{K}$. was described by V. Mathot (Free University of Brussels), along with experimental results on the heat of mixing of hydrogen and deuterium liquids. Another interesting now type of eryostat, a helium-3 cryostat with a lead wire thermal switch for cooling the calorimeter to $0 \cdot 3^{\circ} \mathrm{K}$., was depicted by D. L. Martin (National Research Council of Canada).

The Conference is deeply interested in the adequate presentation of calorimetric and thermodynamic data. For this reason the fifteenth Calorimetry Conference considered carefully and adopted a "Resolution on Publication of Calorimetric and Thermodynamic Data" which is intended to be a guide for authors, editors and referees of calorimetric papers. This resolution is a revision of one adopted in 1953 that has been valuable to authors and editors alike.

Plans were announced for the next conference, which will be an International Calorimetry Conference and will be held at Ottawa during August 14-17, 1961. The meeting will be jointly sponsored by the Calorimetry Conference and by the Subcommission on Experimental Thermochemistry of the Commission on Chemical Thermodynamics of the International Union of Pure and Applied Chemistry. The host organization will be the National Research Council of Canada.

At the annual election the following officers were elected: chairman, Dr. D. W. Osborne (Argonne National Laboratory); chairman-elect, Dr. J. E. Kunzler (Bell Telephone Laboratories); secretarytreasurer, 1960-63, Dr. G. T. Furukawa (National Bureau of Standards) ; directors, 1960-62, Dr. G. T. Armstrong (National Bureau of Standards) and Dr. J. K. Logan (Naval Research Laboratory). Other directors of the Conference are : Dr. J.P. McCullough, Prof. David White (Ohio State University), Prof. N. E. Phillips (University of California, Berkeley), and Prof. J. M. Sturtevant (Yale University).

\title{
THE INTERNATIONAL ASSOCIATION OF VOLCANOLOGY
}

$\mathrm{T}$ HE International Association of Volcanology, under the ægis of the International Union of Geodesy and Geophysies, met in Helsinki during July 25-August 6, with Prof. A. Rittmann, who is a Swiss citizen, as president.

Mr. G. R. Laclavére, in his capacity as interim secretary in place of Prof. F. Signore, who died on December 2, 1959, reported that since the last general assembly in Toronto in 1957, five parts of the Bulletin Volcanologique and six parts of the Catalogue of Active Volcanoes (Africa, Melanesia, Central America, Kurile Islands, Kamchatka and the U.S.A.) had been published, and in September 1958 fifty-four volcanologists, from twelve countries, had met in Paris for a symposium.

In Helsinki, under the presidency of Prof. A. Rittmann, and with the assistance of the local secretary, Prof. Th. G. Sahama, the work of the Association was arranged in four sections: (1) active volcanoes (six papers and six reports) ; (2) physics of volcanoes 
(four papers, also five papers combined with section 1); (3) physical chemistry and chemistry of magmas, volcanic waters and volcanic gases (eighteen papers); (4) palæovoleanology and plutonism (fourteen papers).

Altogether fifty-five contributions were submitted to the Association from fourteen countries, distributed as follows : U.S.S.R. 15, United States 8, France 6, Japan 6, Australia 4, Great Britain 4, Belgium, Italy, Portugal and Switzerland 2 each, India, Mexico, Netherlands and Norway 1 each. Of these contributions forty-three were read and discussed. In addition, two papers on lunar volcanoes were submitted. Prof. A. Rittmann's presidential address dealt with the geochemistry of basalts and the mechanism of their eruption. The national reports on recent volcanic activity were contributed by Australia, India, Japan, Mexico, United States, U.S.S.R.

Severel joint symposia also were held on the subjects of: (1) isotope geology and experimental petrology; (2) the age of minerals, Pre-Cambrian rocks and meteorites; (3) island ares and the ocean floor.

Two discussions were held under the combined auspices of the International Association of Volcanology, the Intermational Association of Seismology and the Geochemical Commission of the International Union of Pure and Applied Chemistry, on the question of the position of geochemistry within the Inter. national Union of Geodesy and Geophysics and other international scientific unions. As a result, a request was made to the Council of the International Union of Geodesy and Geophysics for the establishment of an ad hoc committee on 'Geochemical Problems'. The function of the committee would be: (1) to arrange meetings in the field of geochemistry under the auspices of the committee, or under the joint sponsorship of the committee and other sections of the Union; (2) to promote the furtherance of geochemistry by investigating the possibility of a relationship between the International Union of Geodesy and Geophysics, the International Union of Pure and Applied Chemistry, and any other international body in the field of geology which may be formed.

During the Assembly two volcanological colour films of outstanding interest were shown, illustrating a spectacular basaltic eruption in Hawaii, and also the remarkable achievements of the Belgian expedition which recently studied the lake of molten lava far down in the crater of the Congolese volcano Nyiragongo.

The president, Prof. A. Rittmann (Catania University), announced a decision, taken jointly by the Department of Volcanology of Catania University in Sicily and the Belgian National Centre of Volcanology, to explore the possibility of creating an International Institution for Volcanological Research in Catania, close to Etna.

The Association expressed approval of the Executive Committee's plan to hold two symposia before the next General Assembly, the first to be on the formation of ignimbrites, hyaloclastites and related deposits, and to be held in Catania during October 1961, and the second on the prediction of time and place of volcanic eruptions and the relationship between magmas and the nature of volcanic eruptions, to be held in Tokyo (Japan) during May-June 1962.

The Association also approved the proposal that a Bulletin of Volcanic Eruptions should be instituted. Such a publication, recording briefly current volcanic phenomena, should appear up to four times a year, and it should be distributed to National Sub-Committees for Volcanology and to certain individuals. It is anticipated that the Volcanological Society of Japan will agree to undertake and finance publication and distribution.

Office bearers for the triennium 1960-63 were elected as follows : president, Prof. A. Rittmann (Switzerland); vice-presidents, Prof. V. I. Vlodavetz (U.S.S.R.) and Mr. Gordon A. Macdonald (United States); secretary, Prof. F. Penta (Italy); chairman of Section I, Dr. M. Neumann van Padang (Netherlands); chairman of Section II, Dr. G. S. Gorshkov (U.S.S.R.) ; chairman of Section III, Prof. H. Kuno (Japan); chairman of Section IV, Prof. B. Gèze (France).

\section{UNIVERSITY DEVELOPMENT IN BRITAIN}

\begin{abstract}
THE statement issued by the Association of University Teachers on the problems of university development is one which should be carefully studied by all who are concerned with policy-making in this vitally important field*.

The Association is concerned about the arbitrary way the University Grants Committee has recommended that university expansion should cater for two scientists against one entrant for all other faculties, including medicine and agriculture, and asks that this matter be reconsidered.

Agreeing with the University Grants Committee's estimate that the number of university students in Britain by 1970 should be about 170,000 , the Association believes that present standards of entrance to the university should be maintained, and is of the

" "Some Problems of University Development". Pp. 7. (London : Association of University Teachers, 21 Dawson Place, W.2, 1960.)
18. 6 d.
\end{abstract}

opinion that there should be sufficient applicants of quality to maintain that standard for at least 170,000 places, and that this figure may have to be exceeded.

To cater for the additional 70,000 students for whom places will have to be found in the next ten years, a major operation will be required. This can be done by increasing the size of existing universities or by founding new ones. Recognizing all the attendant dangers to institutions which grow too large, the Association recommends that at least six new universities should be started during the next two years.

The arguments for new universities are strong. Their building cost can be shown to be no greater than that of expanding existing universities, while the difficulty and cost of acquiring land must be less. The contribution that they can make in terms of variations in teaching methods and added range of research is considerable. There should be a deliberate 